\title{
Scève, Claudine.
}

Urbain le mescongneu filz de l'empereur Federic Barberousse. Édition bilingue par Janine Incardona et Pascale Mounier.

Cahiers d'Humanisme et Renaissance 112. Genève : Librairie Droz, 2013. 334 p. ISBN 978-20600-01610-0 (broché) $41 €$.

En fournissant le texte italien paru à la fin $\mathrm{du} \mathrm{XV}^{\mathrm{e}}$ siècle sous le titre Opera iucundissima novamente retrovata del facundissimo et elegantissimo Poeta Meser Ioanne Bocchacio et sa traduction française - adaptation publiée vers 1530 chez Claude Nourry sous le titre Urbain le mescongneu filz de l'empereur Federic Barberousse, Janine Incardona et Pascale Mounier font bien plus que de donner un texte peu connu et rocambolesque. Comme le montre leur extraordinaire travail d'élucidation, de mise en contexte, et de documentation, elles racontent un chapitre de la vie intellectuelle de Lyon dans les années 1530. Leur matériau est foisonnant, chaque nom ouvrant une passionnante exposition sur ce milieu savant, mondain et humaniste. Aussi, mon premier éloge de ce volume touche à son organisation : une très longue introduction, structurée en cercles concentriques amenant au texte même, trois annexes (illustrations, 
tableau des cinq éditions du texte italien, tableau des modifications structurelles du paratexte entre italien et français), un glossaire et un index des noms propres viennent heureusement encadrer des notes de bas de page fournies et éclairantes. Il y a dans ce discret travail des éditrices scientifiques à la fois beaucoup d'érudition, une grande aisance avec les deux langues, et une immense connaissance de la vie littéraire en français et en italien à la Renaissance. C'est là mon deuxième éloge : texte énigmatique, construit pour des interprétations plurielles et paradoxales, le roman présenté par les deux éditrices devient accessible grâce à leur travail de rétablissement des références, de comparaison des versions et de restitution du contexte culturel. Ces éloges, on le devine, se démultiplient en louanges plus précises : ce volume est un modèle pour l'édition et la mise à disposition de textes renaissants.

Attribuée à Boccace pour être considérée au rang des emprunts italiens alors en vogue, l'histoire d'Urbain est basée non pas sur le Décamperont mais sur une version non canonique de la légende de Constantin ${ }^{\text {er }}$, fils de Constance Chlore et de sainte Hélène. L'histoire implique un viol, une naissance, une foi, une reconnaissance. Elle se répand et connaît un vif succès au $\mathrm{XIII}^{\mathrm{e}}$ siècle, jusqu'à devenir un véritable petit roman. Mêlée à d'autres sources italiennes, historiques et religieuses, elle devient une publication incunable prisée, circulant sous le nom de Boccace, sous forme incunable, mais aussi manuscrite et imprimée. La première partie de la préface de l'édition examine la tradition manuscrite et imprimée pour proposer des fourchettes de datation à l'original italien. L'élucidation des jeux de mots et des dédicaces de l'édition lyonnaise et de la traduction française (sans date, postérieure à 1528) donnée vers 1530 identifie la traductrice : Claudine de Scève, sœur du poète. L'un des petits chapitres de l'introduction donne alors un beau portrait du clan des Scève-Vauzelles. Étudiée d'abord d'un point de vue linguistique, puis en regard de l'original italien, la traduction est alors présentée comme une métamorphose générique, qui dépasse la langue employée. Deux longues études, sur « le genre d'Urbano" et "le genre d'Urbain", montrent que le roman à clé de la version italienne devient un roman sentimental dans sa traduction française. En particulier, une belle analyse onomastique des personnages permet de lire une initiation alchimique dans l'original du roman, tandis que la présentation, succincte et claire, de la carrière mal connue de l'imprimeur Claude Nourry situe le roman d'Urbain dans la vogue des Flammette et autres histoires tirées de Boccace. 
Le parti pris méthodologique et éditorial du texte original (italien pour Urbano afin de juger de la traduction française) et de la version originale (française, pour le roman d'Urbain), sans modernisation autres que celles d'usage, signalées dans l'introduction sont, de fait, une belle profession de foi en l'histoire littéraire et la littérature. Consacré tout autant au texte italien qu'au texte français, ce volume présente non pas une histoire mais l'histoire de cette histoire : comment d'une légende faite de plusieurs traditions, naissent un personnage, puis une seconde légende, puis un roman alchimique, puis un roman sentimental. La complexité de cette genèse du texte et de ses interprétations en fait un support idéal pour présenter et expliquer la Renaissance. La langue française, qui se développe alors dans cette émulation de la production italienne, est dans l'âge de l'enrichissement et de l'exploration. Seconde femme traductrice $\mathrm{du} \mathrm{XVI}^{\mathrm{e}}$ siècle, Claudine Scève, qui signe son travail de façon cryptée, explore les diminutifs, les archaïsmes mais aussi les calques, les reprises, et les italianismes. Les lecteurs modernes y liront, avec émotion, les tâtonnements d'une traductrice qui se veut littérale mais aussi éclairante.

La vérité scientifique et le scrupule éditorial en font, tout autant que la rocambolesque histoire d'Urbain, un roman de la Renaissance. En emprunts, miroirs, retournements, c'est l'histoire de cet humanisme lyonnais, en français et en savoirs, qui se donne à lire dans le beau volume procuré par Janine Incardona et Pascale Mounier. Terminons avec un dernier mot d'éloge. C'est un beau livre : de la couverture à la table des matières, tout est pensé et équilibré. Saluons donc, une fois encore, le travail des discrets qui œuvrent chez et pour la maison Droz : éditeurs, traducteurs, annotateurs et imprimeurs. Grâce à eux, Urbain n'est plus méconnu.

HÉLÈNE CAZES

University of Victoria 